Artigo recebido em

13/09/2014

Aprovado em

$24 / 10 / 2014$

FILIPE

FERNANDES

RIBEIRO

MOSTARO

Universidade do Estado do

Rio de Janeiro

- filipemostaro@hotmail.com

Mestrando do PPGCom da

UERJ. Possui graduação

em Comunicação Social

pela UFJF (2006),

especialização em

Jornalismo Esportivo e

Negócios do Esporte pela

FACHA-IGEC-RJ (2012).

Bolsista de Apoio Técnico a Pesquisa do CNPq -

Nível 1A no projeto LEME

- UERJ
Estudos em Jornalismo e Mídia

Vol. 11 No 2

Julho a Dezembro de 2014

ISSNe 1984-6924

\section{O futebol-arte na imprensa nacional: a construção de um estilo de jogo}

\author{
Filipe Fernandes Ribeiro Mostaro
}

\section{Resumo}

Nosso objetivo neste trabalho é realizar um panorama crítico das narrativas encontradas na imprensa nacional sobre o futebol-arte. O recorte temporal estabelecido é o da Copa do Mundo de 1938, quando acreditamos ter nascido a ideia de futebol-arte, até a Copa de 1970, que seria a consolidação deste estilo. Partimos do entendimento de que a ideia de um estilo distinto de praticar o futebol foi edificado em densas narrativas que tiveram como pano de fundo a questão da mestiçagem e a identidade nacional construída nos anos 1930. O potencial mobilizador do futebol e sua importância na nossa sociedade teriam plasmado a representação do futebol-arte como algo tipicamente nacional. Recorreremos aos jornais O Globo, Jornal do Brasil e A Noite para investigar tal questão.

Palavras-chave

imprensa, futebol-arte, copas do mundo, identidade

\begin{abstract}
Our objective in this paper is accomplish a critical overview of the narratives in the national press about football art. The period of study starts in the World Cup 1938, when we believe was born the idea of football art until the World Cup in 1970, which would consolidate this style. We understand that the idea of a distinctive style of football practice was built in dense narratives that have as a backdrop the miscegenation and national identity constructed in the 1930s. The mobilizing potential of football and its importance in our society have shaped the representation of football art as something typically national. We explore the newspapers O Globo, Jornal do Brazil and A Noite to investigate this issue.
\end{abstract}

Keywords

press, football-art, world cups, identity 
1- Tal pensamento se caracteriza por entender que o jornalismo aborda alguns temas de modo espaçado, com notícias diárias fragmentadas e dispersas, sem construir um significado mais amplo e concreto. Seria preciso, então, conectar estas partes para que um encadeamento narrativo cronológico possibilitasse uma melhor compreensão do assunto. (MOTTA,2009)

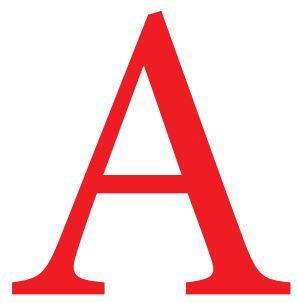

ideia de que além de sermos o "país do futebol" somos o maior exemplo da escola do futebol-arte "bailarino" e "dionisíaco" é frequentemente abordada pela mídia. Neste artigo vamos traçar algumas considerações sobre estilo de jogo e, logo após, demonstrar como a mídia alimentou este discurso ao longo dos anos. Nosso recorte temporal de análise se inicia na Copa de 1938, com as considerações de Gilberto Freyre no artigo Football Mulato, publicado no dia 17 de junho de 1938 no jornal Diários Associados de Pernambuco, e termina na Copa do Mundo de 1970. Partimos do pressuposto de que a Copa de 1938 foi o embrião do nosso estilo distinto de praticar o futebol e de que a Copa de 1970 consolidou toda esta construção. Nosso corpus compreenderá as edições do Jornal do Brasil e $O$ Globo, durante a realização das Copas do Mundo compreendidas no espaço-temporal pesquisado: 1950, 1954, 1958, 1962, 1966 e 1970. Em 1950, também analisamos o jornal $A$ Noite, pela sua importância no cenário midiático e em função do pouco espaço destinado ao esporte no Jornal do Brasil.

A metodologia utilizada será a Análise de Narrativas. Esta metodologia se coaduna de forma apropriada com as questões que pretendemos solucionar neste trabalho. Conforme Motta (2007) aponta, através das análises de narrativas podemos estabelecer sequências de continuidade integrando passado, presente e futuro e construir uma certa "organização" das narrativas, transformando-as em uma única história ${ }^{1}$. Como indica Gilberto Velho, a memória é fragmentada, ou seja, "o sentido da identidade depende em grande parte da organização desses pedaços, fragmentos de fatos e episódios separados" (VELHO, 1994, p.103). Dessa forma, ao unir tais narrativas, estabelecese um maior entendimento de sua continuidade, possibilitando percepções de possíveis descontinuidades.

Entenderemos neste trabalho a construção de uma notícia não como manipulações deliberadas, nem como uma "imitação" do real, mas sim como uma elaboração narrativa com o emprego de aspectos da realidade para produzir um discurso análogo dentro de uma referência sócio-histórica da vida cultural (Cf. SODRÉ, 2009). Consideramos que seja por meio desses recursos acionados pelos meios de comunicação que se construam tais representações (MOSCOVICI, 2012). Além disso, concordamos com Helal e Cabo que as "investigações sobre o discurso da imprensa esportiva em períodos de Copas do Mundo nos ajudam a entender melhor a relação entre imprensa e formação de identidades nacionais pelo meio do esporte". (HELAL e CABO, 2014, p.13).

\section{Estilos de jogo e identidades nacionais}

É importante salientar que ao se pensar uma nação, trava-se uma disputa ideológica entre diversas correntes sociais, cada uma com sua ideologia. O Brasil entrou na década de 1930 com profundas mudanças político-sociais. A industrialização, mesmo que tardia, cresceu de maneira importante. As oligarquias perderiam seu poder com a Revolução de 1930, liderada por Getúlio Dornelles Vargas, que chegou ao governo em 3 de outubro do referido ano. Com o apoio de vários setores da sociedade que pretendiam estabelecer uma nova visão do país, o governo Vargas encontrou uma 
conjuntura política e social, em que se fazia necessário construir um novo pensamento do que vinha a ser brasileiro e, além disso, acomodar diferentes grupos sociais neste novo panorama.

Seguindo o pensamento de Moscovici (2012): era necessário tornarem-se familiares todas essas transformações que eclodiam no país. Entretanto, a tarefa não era simples. Um dos pontos de maior antagonismo de ideias era a questão racial. As reminiscências do escravismo proporcionavam distinções agudas entre as classes sociais e raças no Brasil. Neste último quesito, observava-se, após anos de insensibilidade ao ignorar a contribuição dos escravos em nossa cultura, a presença das três raças: branco, índio e negro, como formadoras da sociedade brasileira. Tal questão dividia opiniões entre a mestiçagem, onde Nina Rodrigues, Silvio Romero e Euclides da Cunha acreditavam que o "embranquecimento" de nossa população seria nossa salvação para o "atraso" (ORTIZ, 2012), enquanto Gilberto Freyre acreditava na mestiçagem como nossa qualidade diferencial entre os outros povos.

Franzini afirma que após o Campeonato Sul-americano de 1919, o jornal O Estado de São Paulo começou a delinear um estilo de jogo nacional: "os jogadores brasileiros evidenciaram possuir as melhores qualidades que se podem desejar em footballer [futebolistas], qualidades que somente eles, e nenhum outro povo, reúnem todas" (FRANZINI, 2003, p.16). Ademais, Franzini indica que em novembro do mesmo ano, o jornalista Americo R Netto retomaria essa ideia para anunciar o surgimento de "certa escola brasileira de futebol, cuja originalidade basear-se-ia no talento individual de nossos atletas". (FRANZINI, 2003, p.16)

O jornalista Americo Netto ainda aponta que o brasileiro havia criado um estilo novo de praticar o futebol, diferente dos europeus, podendo, com este estilo, sermos campeões do mundo. No entanto, as tensões que marcavam construção da identidade nacional também estavam presentes na afirmação de um estilo: buscar algo nacional ou copiar o estilo britânico (cf. Soares e Lovisolo, 2003). Para alguns setores, o modo brasileiro de atuar, individualista, sem disciplina, sem rigor tático, com excesso de dribles e até certo ponto exótico, simbolizava nossa ignorância e não entendimento do que seria o futebol, preconizado pelos ingleses. Era o embate jogador versus equipe, drible versus jogo de equipe. Era o que Oliveira Vianna $(1987)^{2}$ entendia: o brasileiro considerado incapaz de se organizar, sendo individualista, sem sentimentos coletivos e que aguardava um governante redentor para salvá-lo. Para Viana, estas características eram oriundas da mestiçagem e se evidenciavam de forma clara no futebol. Elucidando tal pensamento: os jogadores brasileiros preferiam se destacar de forma individual, sem pensar na equipe e nos companheiros, e em uma jogada definiriam o jogo, sendo o herói, o salvador do time e idolatrado pela torcida. Todavia, este pensamento pessimista sucumbiu na construção da identidade nacional, focada nas ideias de Freyre, antagônicas às de Viana. Além disso, como o contexto histórico pregava uma ruptura com a metrópole, os setores que descreviam nosso estilo de jogo como nossa singularidade e um estilo exclusivo desenvolvido pelas características intrínsecas ao caráter nacional mestiço prevaleceram.
2- A obra que mais apresenta tais argumentos de Viana é Populações meridionais do Brasil, lançado em 1920. A data indicada neste trabalho é da sétima edição do livro lançada em 1987. 


\section{As narrativas do futebol-arte na imprensa nacional}

No dia 17 de junho de 1938, Gilberto Freyre publica, em sua coluna no jornal Diários Associados de Pernambuco, um texto que se torna emblemático na construção da mestiçagem ao nosso futebol e, consequentemente à nossa brasilidade. Intitulado Football Mulato, Freyre diz que o sucesso da equipe está justamente na mistura étnica presente nos jogadores convocados. Além disso, Freyre estabelece uma distinção do nosso estilo de jogo com os dos europeus.

...uma das condições de nosso triunfo, este ano, me parecia a coragem, que afinal tivéramos completa, de mandar à Europa um time fortemente afro-brasileiro. Brancos, alguns, é certo; mas grande número, pretalhões bem brasileiros e mulatos ainda mais brasileiros. [...] O nosso estilo de jogar futebol me parece contrastar com o dos europeus por um conjunto de qualidades de surpresa, de manha, de astúcia, de ligeireza e ao mesmo tempo de espontaneidade individual em que se exprime o mesmo mulatismo de Nilo Peçanha que foi até hoje a melhor afirmação na arte política. Os nossos passes, os nossos pitu's, os nossos despistamentos, os nossos floreios com a bola, o alguma coisa de dança ou capoeiragem que marca o estilo brasileiro de jogar futebol, que arredonda e adoça o jogo inventado pelos ingleses e por eles e por outros europeus jogado tão angulosamente, tudo isso parece exprimir de modo interessantíssimo para psicólogos e sociólogos o mulatismo flamboyant e ao mesmo tempo malandro que está hoje em tudo que é afirmação verdadeira do Brasil (FREYRE, 1938, s/p).

Guterman (2009), também indica que a Copa do Mundo de 1938 é um marco para o futebol como identidade nacional, uma espécie de mito de origem do suposto estilo:
O ano de 1938 é assim o marco histórico, se precisamos de um, da descoberta do Brasil como o "país do futebol", unido de modo nacional à noção de brasilidade emanada de sua seleção em campos estrangeiros, jogando com características próprias e que, com o tempo, se tornariam indissociáveis da própria definição que o brasileiro faria de si mesmo. (GUTERMAN, 2009, p.84)

O Brasil terminou na terceira colocação e Leônidas, artilheiro da competição com oito gols, foi exaltado pelos jornais europeus como o "diamante negro" e o "homem borracha". Pereira e Lovisolo (2014, p.44) afirmam que Leônidas "ganhou notoriedade mundial durante a Copa da França por causa de seu poder de Acreditamos que a denominaţão futehol-apte está intimamente ligada à formação da identidade nacional da décadla de 30

improvisação, que passaria a caracterizar o futebol brasileiro". Leônidas da Silva surgiu como o grande representante deste estilo, instituindo o modelo representativo do que viria a ser o "jogador brasileiro de futebol". Os jornais franceses abordaram da seguinte forma o estilo de jogo de nossos atletas: "os brasileiros são perfeitos artistas com a bola nos pés. Dribles não são segredos para eles. Seus movimentos são ágeis e sua sutileza é notável. Um time formidável" (PEREIRA e LOVISOLO, 2014, p.42). 
Ao seguir as definições de Stuart Hall sobre a construção de identidades na modernidade, partiremos da idéia de que a identidade também se forma na visão dos outros. Tal argumentação indica que através da opinião não só dos jornais franceses, mas dos europeus, forma-se um estereótipo do nosso estilo de jogo agregado ao que seria definido e classificado como tipicamente nacional. Ainda com base no pensamento de Hall, é importante ressaltar que estabelecer a fronteira entre "nós" e "eles" foi fundamental na formação dos estados nacionais latino-americanos ${ }^{3}$. Dessa forma, o futebol seria um terreno fértil para a produção de significados, símbolos e representações do que é "ser brasileiro".

Franzini cita de forma apropriada o pensamento de Freyre na construção do mulato como fator diferencial de nosso esporte:

Nosso futebol mulato, com seus floreios artísticos cuja eficiência - menos na defesa que no ataque - ficou demonstrada brilhantemente nos encontros deste anos com os poloneses e os tcheco-eslovacos, é uma expressão de nossa formação social, democrática como nenhuma e rebelde a excessos de organização interna e externa; a excessos de uniformização, de geometrização, de estandardização; a totalitarismo que façam desaparecer a variação individual ou espontaneidade pessoal. (FREYRE Apud FRANZINI, 2003, p.78)

Deste modo, acreditamos que a denominação futebol-arte está intimamente ligada à formação da identidade nacional nos anos 1930, em que o traço mestiço do brasileiro ganhou força na narrativa do que viria a ser nossa brasilidade. $\mathrm{O}$ futebol se tornou uma cristalização daquele pensamento, principalmente após a Copa do Mundo de 1938, A ideia de democracia racial encontrou no futebol um exemplo de fácil assimilação e compreensão, principalmente pelo potencial mobilizador que o esporte exercia na sociedade (SARMENTO, 2013). Para Soares e Lovisolo (2003), a imagem do que se determinou chamar de "estilo brasileiro de futebol" são da alegria, do improviso, dos dribles, das firulas e serviu para construção dos sentimentos de pertencimento a uma nação miscigenada. Para Franzini (2003, p. 78), Freyre vai definir nosso estilo a partir da contraposição do padrão de cultura apolíneo (formal, racional, ponderado), que seria o estilo europeu, ao passo que, o estilo dionisíaco (individualista, emocional, impulsivo), peculiaridade mestiça "demarcaria a singularidade brasileira".

No futebol brasileiro, a idealização do estilo de jogo do futebol-arte, representação que permanece muito forte até os dias atuais quando se refere à seleção brasileira, tem seu embrião em um artigo do intelectual Gilberto Freyre, escrito para o Jornal o Diário Associados de Pernambuco durante a Copa do Mundo de 1938 na França. "Foot-ball mulato" atribui características dionisíacas ao estilo de jogo brasileiro que estariam diretamente relacionadas aos elementos culturais de um povo miscigenado. Criatividade, espontaneidade, malemolência seriam atributos do futebol brasileiro, oriundos da mistura das raças que formariam a Nação. (SOARES, BARTHOLO e SALVADOR, 2007, p.5)

Assim, as narrativas continuaram com o Estado Novo. Contudo, entendemos que o momento em que as representações sobre estilo de jogo, reforços e ressignificações de identidades nacionais ganham maior intensidadeénas Copasdo Mundo. Andrew Tudor (2006) sugere esta construção de
3- Helal e Cabo (2014), também nos apontam que nossos países vizinhos trilharam um caminho recheado de semelhanças e congruências com a nossa edificação de uma identidade nacional através do futebol. Percebe-se que a construção do futebol como identidade nacional, principalmente para designar uma diferenciação ao modelo europeu é visto tanto no Brasil, como em nossos países vizinhos Argentina e Uruguai. Dessa forma, o estilo de jogo sul-americano confrontaria o estilo europeu de jogo. 
estereótipos esportivos combinados à identidade nacional de forma mais intensa durante estes eventos. O autor observa que os times são conjecturados com traços que derivam da construção histórica de seu caráter nacional. Evidenciando este pensamento é comum observar os clichês do tipo: a seleção japonesa vai jogar baseada na aplicação e dedicação, como os samurais. Já os países nórdicos vão concentrar seu jogo na força física, enquanto os africanos vão demonstrar muita ginga e pouca organização. Tais premissas são constantemente observadas na mídia às vésperas e durante esta competição, indicando um reforço, mesmo que seja impreciso e homogêneo, do que determinado país tem como identidade e, consequentemente, é associado ao seu estilo de jogo. Pablo Alabarces (2008) afirma que "esse esporte foi um forte operador de nacionalidade, construtor de narrativas eficazes para a ideia de identidade nacional específica que varia segundo a conjuntura histórica.” (ALABARCES, 2008, p.27)

Com o fim do Estado Novo, em 1945, e com a experiência democrática, foi necessário definir novas diretrizes nos campos políticos e sociais, o que não retirou do futebol sua relevância na construção do ethos nacional. Mais do que isso, com a escolha do país como sede da Copa do Mundo seguinte, o Brasil viu em tal evento uma chance de se mostrar ao mundo.

Pode-se considerar que o evento foi um sucesso. As apresentações do time brasileiro, principalmente nos jogos do quadrangular final, alimentavam a ideia de um estilo diferenciado e de que tínhamos o melhor futebol do mundo, mesmo sem explicitar o termo futebol-arte. Após as vitórias (ambas no quadrangular final) contra a Suécia, 7 a 1, e Espanha, 6 a 1, é possível identificar elogios exacerbados ao nosso estilo de jogo e, principalmente, a voz dos outros sobre o nosso futebol, um dos fatores de consolidação e construção de uma identidade. (cf. Hall, 2011). O jornal A Noite estampou como manchete da capa a opinião dos italianos, na ocasião bicampeões do Mundo (1934-1938), sobre o nosso futebol: "Esplêndida! Irresistível! Ultrapoderosa - assim a imprensa italiana classifica a equipe brasileira”. (A Noite, 14 jul. 1950, p.1) E completavam com outro comentário dos jornalistas italianos: "Jamais testemunhamos, em nossa carreira jornalística nos sports, fenômeno como o do Brasil". Depois da vitória sobre a Suécia, o jornal $A$ Noite publicou uma entrevista com o técnico do país nórdico, que declarou:

Perdemos para uma equipe que representa uma das forças máximas do football mundial. O "english team" nem nenhum outro quadro teria chance frente ao jogo praticado, hoje, pelos brasileiros. [...] O team brasileiro apresentou-se em campo fazendo lembrar uma orquestra bem regida. (A Noite, 10 jul. 1950, p.12)

Porém, na partida final contra o Uruguai, diante de um Maracanã com mais de 200 mil pessoas, e toda a euforia construída pelos resultados anteriores, a seleção brasileira foi derrotada. O impacto que o megaevento Copa do Mundo causou em nossa sociedade foi grande, inclusive sendo tratado pelo discurso midiático como a "maior tragédia nacional". Essa expressão é explicada por Roberto DaMatta da seguinte forma: "primeiro porque implicou uma coletividade e trouxe a visão solidária de uma oportunidade histórica. Segundo, porque ela ocorreu 
no início de uma década na qual o Brasil buscava marcar o seu lugar como nação que tinha um grande destino a cumprir." (DAMATTA, 1982, p.31)

Entretanto, a derrota de 1950 não modificou a representação do futebolarte construída em 1938. Este trecho no periódico O Globo Sportivo afirma que o melhor time da competição foi o brasileiro: "A qualidade do jogo foi extraordinário e todos os peritos europeus concordaram nesta afirmação que nunca tinham visto um football de tão alto nível técnico e artístico como o selecionado brasileiro frente à Suécia e sobretudo à Espanha”. (O Globo Sportivo, 21 jul. 1950, 13)

Quatro anos mais tarde, durante a Copa do Mundo de 1954, é interessante observar que a Hungria, time que praticava o futebol dito pela imprensa mundial como o mais bonito e envolvente, em nenhum momento recebeu a alcunha de futebolarte pelos jornais brasileiros, como se esta designação fosse exclusiva e registrada como uma "propriedade nacional". Durante toda a Copa do Mundo de 1954, o máximo de elogio que a narrativa do Jornal do Brasil chegou foi a seguinte descrição da equipe húngara:

O onze da Hungria chegou quase a conseguir essa coisa difícil que se chama perfeição. Uma boa defesa e uma das linhas dianteiras mais rápidas do mundo tornaram quase invencíveis esses assombrosos jogadores do Danubio. Os magiares não forma derrotados nos últimos quatro anos, e muitos entendidos de foot-ball opinam que, dentro de quatro anos, não surgirá outra equipe capaz de derrotá-los. Na realidade, para serem vencidos, seus adversários teriam de marcar pelo menos quatro "goals", porque eles raramente fazem menos. (Jornal do Brasil, 24 jun. 1954, Caderno 1, p.12)
Já nas narrativas do jornal $O$ Globo, encontramos poucos elogios aos húngaros e uma maior atenção à seleção nacional.

Em 1958, com o primeiro título nacional e a presença decisiva de Garrincha e Pelé, já encontramos a definição de um estilo de jogo nacional, muito influenciado pelo talento desses dois jogadores. O Jornal do Brasil, em sua edição do dia $1^{\circ}$ de julho, dedica uma página inteira ao olhar estrangeiro sobre o nosso futebol. Os argentinos, por exemplo, assim definiram nosso estilo: triunfou o futebol nativo, contra o
sistema europeu, porque o Brasil re-
presenta esse futebol. É mentira que
seus homens tenham assimilado
as características europeias. Muito
pelo contrário, os seus retumbantes
triunfos alicerçaram-se na incom-
parável habilidade dos seus jogado-
res no domínio da bola". (Jornal do
Brasil, 1 jul. 1958, Caderno1, p.21)

Já o britânico Daily Press afirmou: "Creio que essa final da Copa do Mundo viu no futebol do Brasil o mais próximo da perfeição que onze homens podem alcançar." O Daily Mirror estampou: “O brilhante e mágico futebol dos mestres do Brasil hipnotizou os suecos." E o austríaco Express fez uma distinção aguda entre o estilo de jogo: "Vitória da técnica. O futebol força foi a K.O." Nota-se o intenso embate entre estilo europeu versus sulamericano e força versus arte/talento. Já no O Globo, encontramos uma reportagem sobre o olhar dos franceses sobre o nosso futebol: "Em artigo intitulado "nada a fazer contra o Brasil", escreve "L'Aurore"[...] demonstrou as qualidades que lhe haviam sido observadas contra a União Soviética, qualidades naturais, atléticas, acrobáticas, de destreza”( O Globo, 26 jun. 1958, Caderno 1, p.19). Na mesma página outra notícia do L'Equipe sobre 
4- O termo se refere a música composta por Wagner Maugeri, Lauro Müller, Maugeri Sobrinho e Victor Dagô durante as comemorações da conquista da Copa do Mundo de 1958 pela seleção brasileira.

5- O Planejamento México foi coordenado pelo professor Lamartine e baseava-se no resultado de um estudo feito a partir do treinamento dos atletas do pentatlo militar e da pesquisa esportiva em grandes altitudes nas Olimpíadas da cidade do México em 1968. como os franceses viam nosso futebol: "Como o ponteiro Garrincha, indolente, felino, inspirado, os jogadores brasileiros pareciam ter vindo de outro planeta com suas leis próprias, insensíveis aos pobres mortais do futebol(...)" (O Globo, 26 jun. 1958, Caderno 1, p.19).

Os dribles de Garrincha e os lances de Pelé, principalmente o gol da final em que dá um lençol ou chapéu no zagueiro e faz o gol, redefinem os estereótipos do que viria a ser o estilo nacional. Entretanto, alguns elementos ainda permanecem latentes: dom natural, dribles, floreios, lances de efeito e ofensividade. Era a "certeza" de que "com brasileiro ninguém podia". Nota-se também que nos anos que se sucederam à conquista da Suécia o futebol nacional reforçou sua importância em nossa identidade, reafirmando-se como um símbolo nacional.

Em 1962, o Brasil consolida sua fama de estilo de jogo baseado na técnica de seus jogadores. Com a lesão de Pelé no músculo adutor direito, Garrincha assumiu o posto de principal nome da equipe. Mais do que isso, ele se tornaria símbolo do futebolarte, sendo a síntese do futebol nacional. Bartholo e Soares (2011) descrevem como a biografia do jogador, escrita por Ruy Castro, vai revalidar a história do atleta encarnando significados coletivos sobre o futebol nacional e sobre o "ser brasileiro". "Garrincha seria a tradução e a encarnação do jogo bonito (beautiful game)" (BARTHOLO e SOARES, 2011, p. 55). A imagem de Mané se consolida após esta Copa do Mundo e ajuda muito na edificação do discurso de sermos realmente o país do futebol. Outros elementos de Garrincha ajudam na construção do jeito brasileiro de jogar futebol. "A estética do estilo de jogo de Garrincha pode ser lida como um alento a toda a nação brasileira. Nelson Rodrigues exalta a mestiçagem e o futebol-arte como elementos centrais da brasilidade, metonimizados em Garrincha” (BARTHOLO e SOARES, 2011, p. 71) A imprensa internacional exalta o futebol-arte praticado por Garrincha, reafirmando o discurso:

O futebol brasileiro - conclui Manning (jornalista do Daily Mirror) tem muitos reis para um só trono. Manning mostrou-se surpreso pois lhe disseram que Garrincha era meio burro e que agora ele não pode fazer uma ideia do que é ser inteligente pra os brasileiros. Todos os comentaristas ingleses presentes a Sausalito foram unânimes em considerar o futebol de Garrincha "pura arte". (Jornal do Brasil, 12 jun 1962, caderno 1, p.12)

\section{A consolidação do estilo nacional}

A derrota definida como vexatória pela imprensa na Copa de 1966, onde o Brasil foi eliminado na primeira fase, causou um hiato no discurso de melhor futebol do mundo praticado pela seleção nacional. Depois do bicampeonato, a expectativa desenvolvida pela imprensa foi grande. $\mathrm{O}$ título simbolizaria a hegemonia de nosso futebol frente ao mundo, além da posse definitiva da taça Jules Rimet.

Iniciamos nossa análise sobre a Copa de 1970 enfatizando o planejamento da preparação da seleção para a altitude das cidades-sede da Copa do México. Foi elaborada uma organização minuciosa pelos preparadores físicos da seleção, conhecida como Planejamento México $^{5}$. Os autores Salvador e Soares (2009) relatam de forma detalhada esta preparação e afirmam que apesar de ser exaltada pela imprensa nacional, como mostraremos a seguir, ela ocasionou uma quebra no discurso de que o futebol- 
arte nacional era baseado no improviso e no dom natural. É notório que um dos grandes fatores para a vitória brasileira em 1970 foi o congraçamento do talento dos jogadores com a preparação física, todavia, mesmo com a exaltação do "Planejamento México" na narrativa midiática em 1970, Salvador e Soares afirmam que a memória construída sobre esta competição vai esquecer tal preparação exatamente por ir contra a construção identitária nacional dos anos 1930.

Podemos apontar que o processo de treinamento físico e a elaboração de uma estratégia de adaptação à altitude (baseada nos conhecimentos científicos da época) foram tão importantes para a obtenção da vitória em 1970 quanto a qualidade dos jogadores que compuseram aquela equipe. Entretanto, tais estratégias, vinculadas às imagens de racionalização de meios, ao uso de tecnologias, à disciplina do treinamento, são abafadas ou secundarizadas por não se ajustarem às imagens da "arte", "genialidade" e "malícia" do jogador brasileiro (SALVADOR e SOARES, 2009, p.20).

Assim, pode-se entender que ao negar uma cientificidade por ser algo não familiar ao nosso estilo de jogo, estamos reestabelecendo o vínculo e a memória com a ideia central do que vem a ser o futebol-arte nacional, demonstrando que as identidades são negociadas e repletas de embates entre o que será esquecido e lembrado pelos agentes da memória. Desse modo, o nosso estilo nacional é algo que acontece "naturalmente", sendo desnecessária a preparação e organização, como as narrativas sobre o jogador Garrincha demonstraram ${ }^{6}$.

$\mathrm{Na}$ página 22 do dia 10 de junho do Jornal do Brasil, a matéria intitulada "Chirol diz que a saúde atual se deve a

Guanajuato" traz uma entrevista com o preparador físico da seleção, Chirol, que enfatiza o treino de adaptação à altitude como diferencial da equipe, ressaltando o trabalho científico e o empenho dos jogadores:

Por esse motivo, não concordo com os que afirmam que os jogadores brasileiros não gostam de fazer ginástica. É uma mentira. Tanto gostam que fizeram na Seleção. $\mathrm{O}$ importante é saber comandá-los, dirigi-los, mostrando a eles o que está certo e o que está errado, quais os benefícios e os inconvenientes. (Chirol diz que a saúde atual se deve a Guanajuato, Jornal do Brasil, 10 jun. 1970, caderno 1, p.22)

Interessante notar que o discurso sobre o futebol-arte se redesenha a partir do jogador que será o modelo da época. Em 1962, com Garrincha como herói, seus atributos como jogador serão mais valorizados, enquanto em 1958 ele dividiu com Pelé. Em 1938, por exemplo, Leônidas definiu as características por ser nosso principal jogador. Em 1970, como nossos jogadores, entre eles Pelé, tido como principal pelos meios de comunicação, demonstravam um vigor físico excepcional, é necessário reajustar a narrativa para que ela não fuja dos fatos visíveis e concretos ao receptor.

Este processo indica que as representações convencionam objetos, pessoas e acontecimentos. Ao definir jogadores como Garrincha, Pelé e Leônidas como símbolos do nosso estilo, os sistemas de classificação, as imagens e descrições que constroem esta representação implicam num elo prévio, feito pela memória coletiva do que se entende como futebol-arte, estereotipado nestes atletas que apresentamos. Esta memória coletiva, ou seja, os elos já presentes na sociedade

6- Para um melhor entendimento dessas narrativas, ler: BARTHOLO e SOARES

(2011) 
desde 1938, são frequentemente ativados pelos meios de comunicação, com a busca de antigas seleções e craques que servem de exemplos para estabelecer e provocar reconhecimento das narrativas do futebolarte. Em nossa pesquisa postulamos que a seleção da Copa de 1970, também se tornará um elo quando se pretende definir o que seria o futebol-arte.

A capa do O Globo no dia seguinte da conquista trouxe a seguinte manchete: "Vitória maravilhosa do maior futebol do mundo: 4x1". Destaque para as hipérboles jornalísticas. No Jornal do Brasil a manchete "Brasil tri: A Copa é nossa!" traz a seguinte frase iniciando a matéria: "Quando Carlos Alberto ergueu aos céus a Taça Jules Rimet, hoje à tarde, 700 milhões de pessoas em 50 países comprovaram a supremacia definitiva do futebol-artetécnica-poesia: o Brasil acabava de sagrarse tricampeão do mundo". O grande número de adjetivos empregados na definição do nosso futebol demonstra que a união de outros elementos redefiniria o futebol-arte. As outras reportagens exaltam a qualidade de nossos jogadores, aliada à seriedade e preparação. O futebol regado de talento, mas sem organização, individualista e, às vezes, a indolência dos jogadores era substituída pela aplicação, ao lado de genialidade e coletividade. Em reportagem na página 3 do Jornal do Brasil, Zagalo exalta que a Copa veio com disciplina. Aqui nota-se que Zagalo, obviamente, vai ressaltar o seu lado, afinal o técnico não teria importância se apenas o dom natural vencesse a competição.

Identificar o contexto com que as narrativas são produzidas é peremptório para elucidarmos de forma clara o que se pretendia com o discurso. A derrota de 1966 foi amplamente explicada pela falta de organização e modernização em nosso esporte. Assim, a exaltação da preparação da seleção foi incluída na narrativa, mesmo indo contra as características que seriam intrínsecas ao futebol nacional, construídas em 1938. A unificação de um discurso baseado no talento nacional e na recente organização e disciplina exemplar da seleção pode ser entendida perfeitamente pelas declarações do presidente Médici logo após o jogo, deixando transparente a tentativa do governo de usar o futebol como fator de identificação e integração nacional:

Identifico no sucesso de nossa seleção de futebol, a vitória da unidade e da convergência de esforços, a vitória da inteligência e da bravura, da confiança e da humildade, da constância e da serenidade da capacitação técnica, da preparação física e da consistência moral. Mas é preciso que se diga, sobretudo, que os nossos jogadores venceram porque souberam ser uma harmoniosa equipe, em que, mais alto que a genialidade individual, afirmou-se a vontade coletiva. (Jornal do Brasil, 21 jun. 1970, caderno 1, p.3)

Todavia, já deixamos claro que tais narrativas são repletas de disputas ideológicas e ao longo do tempo se modificam. Foi exatamente isto que ocorreu com o discurso da Copa de 1970. A presença de militares na comissão técnica fez com que nos anos seguintes e preparação e disciplina fossem entendidas por alguns pensadores, Joel Rufino dos Santos (1978) por exemplo, como a militarização do futebol. Supomos que por este motivo encontre-se na memória coletiva atual da Copa de 1970, conforme Salvador e Soares (2009) demonstraram, uma negação e esquecimento da preparação e do "Planejamento México", aliada ao fato de estas características irem 
contra a construção histórica do estilo nacional.

A coluna de Armando Nogueira, reverberando a entrevista do técnico Zagalo que enalteceu a ciência da comissão técnica, no dia após a conquista do Brasil prevê este acontecimento:

Arte e ciência. Essas declarações de Zagallo, leitor, são da maior importância pelo seguinte: o futebol brasileiro, que é o melhor do mundo, costuma equivocar-se no instante da glória. Daqui a pouco, haverá no Brasil uma corrente de opinião, creditando o sucesso do Mundial de 70 ao talento puro do jogador. $\mathrm{E}$ ninguém mais se preocupar com o preparo tático e muito menos com o preparo físico, achando que arte do craque vencerá sozinha a Copa do Mundo, em 74. Nada disso, nada disso. O título de 70 deve ser exaltado como a associação de valores artísticos e científicos. A técnica incomparável de Pelé e de Gérson só levou o futebol brasileiro a final do Asteca, domingo, porque um comando competente soube executar um programa de preparação física e de habilitação tática, a meu ver, tão precioso quanto o espírito de sacrifício dos jogadores. (NOGUEIRA, A. $\mathrm{Na}$ Grande Área. Jornal do Brasil, 23 jun. 1970, caderno 1, p.35)

Além disso, tal esquecimento pode funcionar como uma forma de desvencilhar a anexação que o governo fez do título do tricampeonato. Seria uma forma romântica do pensamento esquerdista de "devolver a seleção para o povo", soltando-a das amarras do militarismo e negando todo e qualquer elemento que sugira uma relação mais íntima com o governo militar, como a disciplina. Também sugerimos que os resultados obtidos nas Copas de 1974 e 1978, e as queixas da aplicação demasiada da tática, fez com que este elemento fosse esquecido ao longo do tempo como algo não importante da Copa de 1970.

Tal fato demonstra que as

identidades são sempre negociadas, no entanto, uma quebra naquilo que é familiar ao futebol-arte, pode causar uma ruptura na representação e na identidade das narrativas midiáticas que fundamentam o nosso estilo nacional. Por isso, as modificações podem ocorrer, mas não na sua estrutura central, sob pena de não mais serem reconhecidas como legítimas.

\section{Considerações Finais}

Ao vencer a competição e reafirmar a condição de campeões do mundo, a seleção brasileira fica em definitivo com a Taça Jules Rimet, objeto que simboliza as três conquistas do Brasil. A euforia por este feito fez a narrativa buscar elementos importantes não só na conquista de 1970, mas também nas duas anteriores no intuito de consolidar o discurso que vinha sendo construído desde os anos 1930. Começase a comparar as seleções para identificar semelhanças e deslocar diferenças para unificar o discurso do "país tricampeão do Mundo". Neste deslocamento, sugerimos que a preparação física, algo não familiar, foi retirado por não se encaixar na homogeneização do que seria o nosso futebol-arte, agora remodelado por elementos em comum das três conquistas e tendo a seleção de 1970, mundialmente conhecida pela transmissão televisiva, como seu maior ícone. Nesta reconstrução, a preparação física, inegável pilar da conquista no México, ficou apenas na memória de quem viveu aquele momento e de estudiosos sobre o assunto.

Deste modo, a seleção da Copa de 1970 serviu para demarcar o que seria o futebol-arte. Toda a construção de um 
suposto estilo se concretiza nesta Copa do Mundo. A brasilidade exercida por meio do futebol instaura um marco a partir desta competição, ocasionando uma "obrigação" das futuras seleções de seguirem este estilo. A identidade nacional construída nos anos 1930 e a intenção do governo Vargas em usar o esporte para unificar o país ganha um capítulo crucial em 1970. O tricampeonato mundial de nossa seleção reafirma que as representações instauradas quarenta anos antes ainda fazem sentido na sociedade, afinal "somos o maior campeão do mundo", detentores do troféu e "nosso" talento é mundialmente reconhecido, tornando a construção romântica e mitológica de "nosso" estilo de jogo um importante elemento da identidade nacional.

\section{Referências bibliográficas}

ALABARCES, Pablo. Fútbol y pátria: el fútbol y lãs narrativas de la nación em La Argentina. Buenos Aires: Preometeo Libros, 2008.

A Noite, Rio de Janeiro, 20 mai-16 jul 1950. Esportes, Caderno 2, p.1-10.

BARTHOLO, Tiago e SOARES, Antônio Jorge Soares. Mané Garrincha como síntese da identidade do futebol brasileiro. In: HELAL, Ronaldo; LOVISOLO, Hugo; SOARES, Antonio Jorge. (Orgs.) Futebol, Jornalismo e Ciências Sociais: interações. Rio de Janeiro, EDUERJ, 2011.

DAMATTA, Roberto (org.). Universo do futebol: esporte e sociedade brasileira. Rio de Janeiro: Pinakotheke, 1982.

FRANZINI, Fábio. Corações na ponta da chuteira: capítulos iniciais da história do futebol brasileiro (1919-1938). Rio de Janeiro: DP\&A, 2003.

FREYRE, Gilberto. Foot-ball mulato. Diário de Pernambuco, Recife, 17 jun. 1938, p.4.

GUTERMAN, Marcos. O futebol explica o Brasil: uma história da maior expressão popular do país. São Paulo: Contexto, 2009.

HALL, Stuart. A Identidade Cultural na Pós-Modernidade. Tradução: Tomaz Tadeu da Silva. Rio de Janeiro: DP\& A Editora, 2011.

HELAL, Ronaldo e CABO, Álvaro. Copas do Mundo e identidade nacional: um panorama teórico. In: HELAL, Ronaldo; CABO, Álvaro (Orgs.). Copas do Mundo: comunicação e identidade cultural no país do futebol. Rio de Janeiro: EdUERJ, 2014.

Jornal do Brasil, Rio de Janeiro, 24 jun - 18 jul, 1950, Caderno 1, p.10-20.

16 jun - 4 jul, 1954, Caderno1, p.18-24.

8 jun - 1 jul, 1958, Caderno 1, p.15-22.

30 mai - 17 jun, 1962, Caderno 1, p.16-22.

11 jul - 30 jul, 1966, Caderno 2, p.22-28.

31 mai - 23 jun, 1970, Caderno 2, p.15-24.

MOSCOVICI, Serge. Representações sociais: investigações em pscicologia social. Trad. Pedrinho A. Guareschi. 9 ed. Petrópolis: Vozes, 2012.

MOTTA, Luiz Gonzaga. Análise pragmática da narrativa jornalística. In: LAGO, Claudia 
e BENETTI, Márcia. Metodologia de pesquisa em Jornalismo. Petrópolis: Vozes, 2007.

O Globo, Rio de Janeiro, 1 jun - 31 jul, 1950, Caderno 2, p.12-18.

16 jun -4 jul, 1954, Caderno 2, p.14-17.

8 jun - 1 jul, 1958, Caderno 1, p.22-26.

30 mai - 17 jun,1962, Caderno 1, p.20-26.

11 jul - 30 jul, 1966, Caderno 1, p.22-28.

31 mai - 23 jun, 1970, Caderno 2, p.15-28.

ORTIZ, Renato. Cultura brasileira e identidade nacional. São Paulo: Brasiliense, 2012. $14^{\text {a }}$ reimpressão. $5^{\text {a }}$ edição.

PEREIRA, Camila e LOVISOLO, Hugo. 1938: o nascimento mítico do futebol-arte brasileiro. In: HELAL, Ronaldo; CABO, Álvaro (Orgs.). Copas do Mundo: comunicação e identidade cultural no país do futebol. Rio de Janeiro: EdUERJ, 2014.

SALVADOR, Marco Antônio Santoro e SOARES, Antonio Jorge Gonçalves. A memória da Copa de 1970 - esquecimentos e lembranças do futebol na construção da identidade nacional. Campinas: Autores Associados, 2009.

SANTOS, Joel Rufino. "Na CBD até o papagaio bate continência”. In: Encontros com a Civilização Brasileira, número 5, Rio de Janeiro, Civilização Brasileira, 1978.

SARMENTO, Carlos Eduardo Barbosa. A construção da nação canarinho: uma história institucional da seleção brasileira de futebol, 1914-1970. Rio de Janeiro: Editora FGV, 2013.

SOARES, Antonio Jorge G.; BARTHOLO, Tiago L.; SALVADOR, Marco S.. A imprensa e a memória do futebol brasileiro. In: Rev. Port. Cien. Desp., Porto, v. 7, n. 3, dez. 2007. SOARES, Antonio Jorge Gonçalves e LOVISOLO, Hugo. Futebol: a construção histórica do estilo nacional. In: Revista Brasileira de Ciências do Esporte, v.25, n.1, Campinas, Autores Associados, p.129-143 set. de 2003.

SODRÉ, Muniz. A narração do fato: notas para uma teoria do acontecimento. Petrópolis: Vozes, 2009.

TUDOR, Andrew. "World Cup Worlds: media coverage of The Soccer World Cup 1974 to 2002. In: RANEY, A. e BRYANT, J. (orgs.). Handbook of sports and media. Nova York: Routledge, 2006.

VIANA, Francisco José Oliveira. Populações Meridionais do Brasil: populações rurais do centro-sul. 7 ${ }^{\text {a }}$ Ed. Belo Horizonte/Niterói, Itatiaia/Eduff, 1987, 2 vols.

VELHO, Gilberto. Projeto e Metamorfose: antropologia das sociedades complexas. Rio de Janeiro: Zahar, 1994.

Estudos em Jornalismo e Mídia está sob a Licença Creative Commons 2.5 